\title{
Donut Stop: \\ Local Competition From A National Chain
}

Neil Terry, West Texas A\&M University, USA

Karyn Friske, West Texas A\&M University, USA

Duane Rosa, West Texas A\&M University, USA

James Owens, West Texas A\&M University, USA

\begin{abstract}
This case applies undergraduate intermediate microeconomic competition fundamentals to the situation of a dominant local firm competing against a national company. The case presents details of a donut company with multiple locations in a mid-sized city competing against a national chain with more than 175 stores. Price, location, attribute differences, firm-service differentials, and differentiated subjective image in the form of advertising are the primary forms of competition explored in the case.
\end{abstract}

Keywords: Advertising, competition, market entry, and microeconomic theory.

\section{INTRODUCTION}

ith the comforting sound of morning conversations and the smell of fresh donuts in the background, Rosemartha looks out her window and ponders the future of the Donut Stop. Although firmly established for almost thirty years, the family business faces the prospect of a national franchise entering the region. Rosemartha believes competition is good for any business, but wonders how to prepare for the arrival of Krispy Kreme in Amarillo, Texas.

\section{BACKGROUND}

Rosemartha thinks back to the day when her mother-in-law said, "Let's open a donut shop." Rosemartha and her husband, Jim, had moved back to their hometown and were interested in starting a business. They were young and enthusiastic, and thought donuts sounded like a great opportunity. Although Rosemartha and Jim had no experience in the donut business, Jim's mother had previously worked for Spudnuts and knew about donut-making. In August 1974, Rosemartha and Jim opened the first Donut Stop in Amarillo, Texas with an initial investment of $\$ 2,500$ and no formal business plan. Shortly after that, a second shop opened and donuts were made in one location and transported to the other. In 1979, they bought a donut mix recipe and began doing their own blending. They bought local ingredients from local businesses like Holly Sugar. About ten years into the business, they became a Subchapter S corporation, and later formed two companies, the Donut Stop and a separate property business. The company grew to as many as eleven stores in the Amarillo area, averaging approximately ninety employees at all locations combined.

Owning and operating a business has provided Rosemartha and Jim an excellent applied business education. They learned many important things over the course of thirty years in the donut business. Since the beginning, they were very customer-oriented and hired people with a similar philosophy. Their aim is to think like a customer. For instance, since most customers prefer hot fresh donuts when they come to the shop, the Donut Stop cooks donuts fresh as needed. This means they can use fewer preservatives. Their process of hand-cutting donuts allows them to make twists, fritters, and other unique specialty items.

As an active participant in day-to-day operations, Rosemartha has always known all the employees and many of the customers by name. She goes to the various locations and pitches in and does whatever is needed from 
mopping the floors to making a bank run for change. Several Donut Stop employees have been with the company since the beginning. Customers and employees are fiercely loyal. In addition, the Donut Stop is very kid-friendly, since children are important customers in the donut business. Business is better on days when children are out of school.

Donuts are all about location. Rosemartha and Jim learned from experience that to be successful, a store must be on the going-to-work side of the road. Furthermore, donuts are inexpensive and as such are not dependent on sales to higher-level socioeconomic groups located in upscale neighborhoods.

\section{COMPETITION CONCERN FOR THE DONUT STOP}

In 2001, the Donut Stop owners heard rumors that Krispy Kreme was considering Amarillo. Rosemartha was concerned even though they had survived competition from Dunkin' Donuts in the early years. That seemed like friendly competition whereas Krispy Kreme seemed more threatening. Krispy Kreme had become a pop culture phenomenon. It had a reputation of coming into a new town amid a huge amount of hype. In fact, the buzz started long before Krispy Kreme ever came to Amarillo. Krispy Kreme publicized its involvement with charitable groups in the form of sales to church groups for fundraisers. A favorite fundraiser for many youth groups in Amarillo was to send a parent on an extended evening trip to Dallas (approximately a 12 hour round trip) to pick up numerous boxes of the famous donuts and bring them back in time to sell at makeshift stands in parking lots as church let out on Sunday morning. There was already that mystique and desire for something hard to get. In addition, Krispy Kreme is known for its donut theaters or glassed area for watching the automated donut-making process.

When it became official that Krispy Kreme was opening a franchise in Amarillo, Jim went all over the U.S. to visit stores where there was strong local competition. Although Rosemartha was extremely concerned, Jim was confident the Donut Stop would survive. He learned that Krispy Kreme Doughnuts are formed from dough extruded by air pressure to form a perfect donut shape. That means that there are no donut holes at Krispy Kreme. The Donut Stop hand-cuts their donuts, which means they do have donut holes, a favorite among the younger set. Handcuts are required for special items such as twists, cinnamon rolls, fritters and clusters. In addition, the Krispy Kreme stores are franchises, which must use only Krispy Kreme ingredients, recipes, and equipment. They are limited in their ability to introduce cherry frosting, red and green holiday donuts, or other specialty items.

Before the Krispy Kreme announcement of entering the Amarillo market, the Donut Stop already owned property at Interstate- 40 and Bell where they planned to open a megastore with automatic donut making machine, a donut theater, a kitchen for hand-cut donuts, and a specialty coffee shop. Their architect son designed a unique eyecatching art deco building with huge windows and big circular booths inside. They hoped to have it open before Krispy Kreme arrived. In addition, they had plans in the works to remodel several other existing stores.

As they approached their thirtieth year in business, Rosemartha and Jim face a serious threat to the Donut Stop. Rosemartha has a legitimate reason to be concerned since the nationally known Krispy Kreme was opening at a time when there was already pressure on donut sales due to increasing interest in low carbohydrate diets and healthy low fat and low sugar diets. The owners of the Donut Stop must consider how to maintain their market share in a changing competitive environment.

\section{KRISPY KREME BACKGROUND}

The history of Krispy Kreme Doughnuts is the story of one man: Vernon Rudolph. After graduating from high school, Vernon started working for his uncle, Ishmael Armstrong, who had bought a donut shop in Paducah, Kentucky, along with a secret recipe for yeast-raised donuts. In 1933 Rudolph started selling the yeast donuts door to door for the Krispy Kreme Donut Shop. Not only did Rudolph sell donuts, he took part in making them, which gave him an all around experience in the donut business.

Vernon Rudolph, however, wanted to open his own Krispy Kreme store. So, in the summer of 1937, he left Nashville with two friends. They had stopped in Peoria, Illinois, but found rents too high in that part of the country. The story goes that he took a pack of Camel cigarettes from his pocket and noticed that they were manufactured in 
Winston-Salem, North Carolina. He thought that this might be the best place for his donut shop since the town had a nationally advertised tobacco product. With only $\$ 25$ left, they rented space in a building on South Main Street in Winston-Salem, North Carolina. They were able to get the ingredients and some equipment on credit and started making yeast donuts.

Krispy Kreme started out primarily as a wholesale business. Using trucks to deliver the donuts, Rudolph was able to sell the product throughout the area. However, the aroma of fresh donuts being made each day caught the attention of passersby, and this led to the beginning of Krispy Kreme's retail operation.

Rudolph wanted to expand his operation, so he opened other stores in the area. However, instead of Rudolph owning all of them outright, he entered into partnerships or into associate (franchise) relationships. These partnership/franchise arrangements gave the operators the use of the Krispy Kreme name, the recipe for the donuts, and the ingredients. Rudolph required them to adhere to a philosophy of producing only the highest-quality donuts.

In 1946, Rudolph consolidated all the Krispy Kreme resources together under the corporate ownership of Krispy Kreme Donut Company in order to allow the firm to grow and give the shops a sense of uniformity. Then, in 1947 he formed the Krispy Kreme Corporation. The donut company was responsible for the individual store operations while the Krispy Kreme Corporation produced the dry mixes used by the shops. Vernon Rudolph served as President and Chairman of the Board.

Krispy Kreme Corporation has always been very innovative for the donut industry. They formed three departments, a Mix Department, a Laboratory, and an Equipment Department. The primary mission of the Mix Department was to mix, in bulk, the key ingredients needed by all the shops to make the donut products, which included yeast and cake donuts, and new products, such as fried pies and honey buns. By providing uniform mixes, Krispy Kreme was able to ensure that all stores produced the same quality of products. The Laboratory was created in 1949. It tested the ingredients and experimented with others to see if they could produce a better product following on Vernon Rudolph's belief in having top quality and uniformity. The Equipment department was formed because the main supplier of yeast donut machines at the time, the Donut Corporation of America, decided to produce their own donuts. So starting in 1949 Krispy Kreme began to manufacture its own equipment.

By the 1960s, Krispy Kreme was well-known throughout the Southeastern United States and began to expand into other areas of the country. Then on August 16, 1973 Vernon Rudolph who had led the company from its beginnings died. This led to some very difficult years for Krispy Kreme. In 1976 they merged with Beatrice Foods Company of Chicago.

Beatrice Foods encouraged the firm to make additions to its menu and substitutions of ingredients in order make additional profit for the firm. However, by 1981 Krispy Kreme was not as profitable as expected and the company decided to sell the subsidiary. A group of Krispy Kreme associates headed by Joseph McAleer, who had worked for the company thirty years and owned shops in Alabama and Mississippi, formed an investment group and bought the company. McAleer steered the company back to its traditional emphasis on top quality donuts as well as on a family atmosphere for employees within the corporation. In the 1990s, Krispy Kreme started expansion outside the Southeastern part of the U.S. Today, they have locations in most states and in Canada.

On May 6, 2002, Krispy Kreme announced that it awarded development rights to five new market areas in the states of Texas, Wyoming, and Montana. According to the press release, KK-TX, LLC was to develop stores in Lubbock and Amarillo, Texas. Hal Smith, who was the current Krispy Kreme franchisee in Oklahoma City and Tulsa, Oklahoma, was to become managing partner of the new venture with Krispy Kreme Donut Corporation retaining $33 \%$ of the venture. Smith had extensive experience in the restaurant industry and was the former President of Steak \& Ale, former President/Chief Operating Officer of Chili's Inc. and former Chairman, CEO and President of Chi-Chi's Mexican Restaurants. His company, Hal Smith Restaurant Group, operated twenty-six full service restaurants in six states. 


\section{KRISPY KREME IN AMARILLO}

Before Amarillo and Lubbock, Krispy Kreme had not previously pursued franchise opportunities in communities with a base population of less than 250,000. Headquartered in Winston-Salem, NC, the company had successfully gone public in 2000 and was listed on the NYSE in 2001. In early 2001, Krispy Kreme had 174 stores in the United States with 111 of those being franchised stores and the remainder company owned. They planned to open an additional thirty-six units in 2002 with all of them being franchise operations including the one planned for Amarillo. Total revenue in the fiscal year ending in January, 2002 was $\$ 394.4 \mathrm{M}$ with a net income of \$26.4M. Seventy-one percent of the revenue came from the actual sales of donuts with an additional $3 \%$ from franchise fees and approximately $26 \%$ from the sale of machinery and raw materials to the franchise stores.

Amarillo, with a population of approximately 200,000, was the first small market entrance for Krispy Kreme. The site chosen for the new Krispy Kreme facility was highly visible from Interstate-40 and less than a mile from the Donut Stop's planned new flagship store on the corner of Bell Street and Interstate-40. Although the property was on the same side of the major interstate, the Krispy Kreme store was inconveniently located on the one-way access road in the middle of the block after the entrance ramp and before the exit ramp. A formal groundbreaking ceremony, with boxes of free donuts, took place in July 2002. Management announced that the 4,000 square foot Krispy Kreme "factory" in Amarillo was expected to open in fall 2002 and would employ approximately 80-125 people.

Newspaper coverage, both before and after the arrival of Krispy Kreme, was amazing. Numerous articles were published discussing competition with Donut Stop, customer loyalty, and the nationwide Krispy Kreme craze.

Krispy Kreme opened in Amarillo on Election Day, November 5, 2002. Based on previous store openings, they were prepared for huge crowds, possibly more than 4,000 people, with drive-through line waits of up to an hour or longer. They hired three off-duty police officers to direct traffic. One couple arrived on November 3 and camped out in order to be the first customers. They were joined the next day by several high school students from a nearby town whose parents allowed them to skip school in order to be a part of the grand opening experience. On opening day, there were about eighty cars waiting in line but the hour long waits quickly dissipated. After the arrival of Krispy Kreme, a locally owned convenience store business switched from Donut Stop to Krispy Kreme, allegedly, because their donuts had a longer shelf life. In addition, the Donut Stop lost one employee to the competition.

\section{THEORETICAL FOUNDATION}

Companies can compete in several possible ways. In this case involving the Donut Stop, the primary outlets for competition are based on price, location, attribute differences, firm-service differentials, and differentiated subjective image in the form of advertising. This section puts forth a brief theoretical foundation for all five forms of competition and a brief application to the case.

Price is a traditional outlet for competition. The number of companies in a market often influences the nature of price competition. Limited competition derived from two to four firms could yield aggressive price competition in the short-run but often results in a mutual interdependence of limited price competition in the longrun. Donuts are not an expensive purchase for most consumers yielding the possibility that price elasticity of demand is of limited importance. On the other hand, it is possible that consumers view donuts as an inexpensive treat that is more rewarding at a value price.

Location can be an important aspect of competition. Sales can be highly influenced by traffic flows during business hours and consumers often value convenience shopping, especially for a small ticket item like donuts. Donut sales are highly concentrated in the morning hours, implying a location consistent with easy access for traffic to work is most desirable. Ambiance can also be a location consideration for donuts, with some places offering patrons square footage to drink a cup of coffee and read the newspaper while consuming a donut.

Products often have unique attribute differences that influence consumer preferences. The attribute differences could be very clear attributes like a silk suit versus a cotton-polyester blend suit. Even minor attribute 
differences could yield a strong consumer preference for various individuals, as illustrated by loyal patrons of PepsiCola versus Coca-Cola. Donuts offer significant attribute differentiation. There are obvious variations in donut flavors, which include chocolate, glaze, maple, twist, cream filled, and numerous additional flavors. More subtle attribute differences for donuts include holding time before disposal, preservative use, sugar content, and hand versus machine production.

Firm-service differentials can greatly influence the consumer shopping experience. Some companies might focus on friendly service that is customer-oriented and builds relationships. A second approach to service is a primary focus on expeditious service or customer convenience. The purchase of small ticket items with limited price variation is often influenced by firm service differentials.

Advertising is a competitive outlet that allows a firm to announce product existence, price, location, and/or quality. Unlike price cuts, the initiator of an advertising campaign may enjoy market share and profit gains with retaliation taking weeks or months. Advertising can be an outlet for aggressive instincts in markets that are not suited for price competition. In general, donut prices are relatively stable and not typical of a product conducive to aggressive price competition because the purchase is relatively small as a percent of income. Donuts are a low price but high volume product, which makes it a natural industry to compete via advertising and subjective image.

\section{CASE QUESTIONS FOR CLASS DISCUSSION}

What competitive actions should a regional company like the Donut Stop take in order to maintain market share given the market entry of a national company like Krispy Kreme? There are no explicit answers to the Donut Stop case but there are several points worthy of discussion in an intermediate microeconomic theory course. Before reading the epilogue to find out how the case was resolved, answer and discuss the following questions relating to the Donut Stop case:

(1) What are the advantages and disadvantages of Donut Stop lowering price and creating price competition? Are there creative ways the Donut Stop could create price competition without explicitly lowering price?

(2) The Donut Stop is an established company with a physical presence at eight different locations. Krispy Kreme is limited to one physical location but a delivery contract with a local convenience store that increases product placement to over a dozen locations. What location advantages exist for the Donut Stop? Is there anything the Donut Stop can do to improve or accentuate location as a competitive advantage? The Donut Stop offers hand-cut donuts versus the air pressure machines employed by Krispy Kreme. In addition, the holding time for Donut Stop donuts are limited to a few hours in order to ensure freshness versus a much longer holding time for Krispy Kreme doughnuts created by the consistent formation of one style of air pressure donut combined with preservatives. How can the Donut Stop approach attribute differences to create a competitive advantage?

(4) The Donut Stop is a locally-owned company with a thirty-year relationship with the community. Krispy Kreme is a national chain arriving in the new market with significant publicity. How can the Donut Stop use their experience to create a competitive advantage based on firm-service differentials? Can Krispy Kreme do anything to create a firm-service differential advantage?

(5) Historically, the Donut Stop never felt the need to do any formal advertising but the arrival of Krispy Kreme created a new challenge. How should the Donut Stop create differentiated subjective image in the form of advertising? Are there any moderate expense advertising opportunities the Donut Stop should pursue? Are there any substantive advertising opportunities the Donut Stop should pursue?

\section{EPILOGUE}

The Donut Stop regional battle against the market entry of Krispy Kreme is a case with multiple competitive actions. This section offers a discussion regarding the competitive response of Donut Stop to the market entry and concludes with clear case resolution.

The Donut Stop response to the market entry of Krispy Kreme with respect to price competition was aggressive. The entry of Krispy Kreme into the market coincided with the thirty-year anniversary of the Donut 
Stop. The Donut Stop offered donuts at a sale price of thirty cents to celebrate the anniversary. The Donut Stop also offered a Wednesday special of six donuts for ninety-seven cents as part of a promotion with a local radio station. Franchise restrictions limited the ability of Krispy Kreme to match the sale price. Krispy Kreme did offer a special giving some patrons a free donut. In addition, Krispy Kreme put forth an effort to package product as part of a fundraising initiative for local non-profits. Despite the highly publicized grand opening of Krispy Kreme, Donut Stop sales in the region fell by less than five percent in first month and less then one percent by month three.

Location played an important role in this case. Donut Stop covered the region with eight locations versus the one physical location for Krispy Kreme. In addition, the Krispy Kreme single location was not ideal for morning traffic flows. Future location prospects also favored the Donut Stop, which had committed to building or remodeling three locations before the announced market entry of Krispy Kreme. The Donut Stop familiarity with the region and traffic flows clearly helped dominate the location aspect of the competition game.

Attribute differences also played an important role for the Donut Stop case. Unlike Krispy Kreme, Donut Stop locations are all hot stores with cooking completed on premise. The hot store model allows the Donut Stop the ability to employ a four-hour shelf life policy in order to provide the customer with a hot and fresh product. In addition, Krispy Kreme employs a donut making extruder versus the Donut Stop model of hand cutting some donut types (e.g., twist) in order to enhance taste. The Krispy Kreme mechanized production approach limited the ability to produce diverse goods including donut holes and decorated donuts for the holiday season.

Donuts are not a product where firm-service differentials are normally going to be an important determinant of competitive advantage. Donut Stop owners traveled to multiple Krispy Kreme locations in several different states in order to evaluate business model, product, and service of the highly acclaimed competitor. The Donut Stop clearly holds an implicit advantage based on the thirty-year relationship with customers in the region. Many of the Donut Stop employees have been with firm for several years, including one employee with over twenty years of service. Only one of eighty-eight Donut Stop employees left for a position with Krispy Kreme. In addition, the Donut Stop tries to buy inputs and supplies from local vendors in order to maintain a strong vertical relationship with the regional business community.

The Donut Stop never engaged in serious advertising activities before the announcement of Krispy Kreme entering the market. The Krispy Kreme threat resulted in the Donut Stop hiring a professional advertising consultant. Krispy Kreme received a significant amount of free publicity upon entering the market. The Donut Stop response to the free publicity was to request media outlets mentioning the grand opening of Krispy Kreme also acknowledge the thirty-year anniversary of the Donut Stop. The Donut Stop also engaged in traditional advertising in print and radio outlets. Explicit efforts were made to advertise unique Donut Stop cherry donuts, twists, and donut holes with names like Cherry Baby, Twisted Sister, and Holy Moly. In addition, the entry of Krispy Kreme created a closer bond between the local community and the Donut Stop as survival against a national firm requires support from the local customer base. In return, the Donut Stop focused on visible community outreach projects including augmented contributions to charitable causes and the creation of a college fund.

The story of Krispy Kreme entering the Amarillo, Texas regional market as a franchise is a short story. Krispy Kreme struggled in the region shortly after their November opening. Only a month after opening, Krispy Kreme eliminated approximately twenty positions bringing the number of employees down to eighty and creating negative publicity in the local community with the Christmas season layoffs. Krispy Kreme opened in November 2002 and closed July 2005. Despite a long history of success in the Southeast, Krispy Kreme has struggled to find success in most southwestern cities. The case of the Donut Stop is typical of the problem Krispy Kreme has faced throughout the region. The long-term tie to the community and multiple locations were two of the biggest factors contributing to the success of Donut Stop in this case. In retrospect, Rosemartha concluded that the Krispy Kreme event resulted in the Donut Stop improving as a company that was better prepared to compete in the future against other regional companies, grocery store bakeries, or the potential entry of another national chain like Dunkin' Donuts. 


\section{AUTHOR INFORMATION}

Dr. Neil Terry is dean and professor of economics at West Texas A\&M University in Canyon, Texas. Dr. Terry earned a doctorate degree in economics from Texas Tech University.

Dr. Karyn Friske is the Pickens Professor of Business and associate professor of accounting at West Texas A\&M University in Canyon, Texas. Dr. Friske earned a doctorate degree in accounting from Texas A\&M University.

Dr. Duane Rosa is professor of economics at West Texas A\&M University in Canyon, Texas. Dr. Rosa earned a doctorate degree in economics from Texas Tech University.

Dr. James Owens is department head and professor of finance at West Texas A\&M University in Canyon, Texas. Dr. Owens earned a doctorate degree in finance from Harvard University.

\section{NOTES}


NOTES 